\title{
Epigenome-wide association study for pesticide (Permethrin and DEET) induced DNA methylation epimutation biomarkers for specific transgenerational disease
}

\author{
Jennifer L. M. Thorson, Daniel Beck, Millissia Ben Maamar, Eric E. Nilsson and Michael K. Skinner* (1)
}

\begin{abstract}
Background: Permethrin and N,N-diethyl-meta-toluamide (DEET) are the pesticides and insect repellent most commonly used by humans. These pesticides have been shown to promote the epigenetic transgenerational inheritance of disease in rats. The current study was designed as an epigenome-wide association study (EWAS) to identify potential sperm DNA methylation epimutation biomarkers for specific transgenerational disease.

Methods: Outbred Sprague Dawley gestating female rats (F0) were transiently exposed during fetal gonadal sex determination to the pesticide combination including Permethrin and DEET. The F3 generation great-grand offspring within the pesticide lineage were aged to 1 year. The transgenerational adult male rat sperm were collected from individuals with single and multiple diseases and compared to non-diseased animals to identify differential DNA methylation regions (DMRs) as biomarkers for specific transgenerational disease.

Results: The exposure of gestating female rats to a permethrin and DEET pesticide combination promoted transgenerational testis disease, prostate disease, kidney disease, and the presence of multiple disease in the subsequent F3 generation greatgrand offspring. The disease DMRs were found to be disease specific with negligible overlap between different diseases. The genomic features of $\mathrm{CpG}$ density, DMR length, and chromosomal locations of the disease specific DMRs were investigated. Interestingly, the majority of the disease specific sperm DMR associated genes have been previously found to be linked to relevant disease specific genes.
\end{abstract}

Conclusions: Observations demonstrate the EWAS approach identified disease specific biomarkers that can be potentially used to assess transgenerational disease susceptibility and facilitate the clinical management of environmentally induced pathology.

Keywords: EWAS, Permethrin, N,N-diethyl-meta-toluamide, Transgenerational, Sperm, Testis, Prostate, Kidney, Multiple disease, Pathology

\footnotetext{
* Correspondence: skinner@wsu.edu

Center for Reproductive Biology, School of Biological Sciences, Washington

State University, Pullman, WA 99164-4236, USA
}

C C The Author(s). 2020 Open Access This article is licensed under a Creative Commons Attribution 4.0 International License, which permits use, sharing, adaptation, distribution and reproduction in any medium or format, as long as you give appropriate credit to the original author(s) and the source, provide a link to the Creative Commons licence, and indicate if changes were made. The images or other third party material in this article are included in the article's Creative Commons licence, unless indicated otherwise in a credit line to the material. If material is not included in the article's Creative Commons licence and your intended use is not permitted by statutory regulation or exceeds the permitted use, you will need to obtain permission directly from the copyright holder. To view a copy of this licence, visit http://creativecommons.org/licenses/by/4.0/. The Creative Commons Public Domain Dedication waiver (http://creativecommons.org/publicdomain/zero/1.0/) applies to the data made available in this article, unless otherwise stated in a credit line to the data. 


\section{Background}

The human population is nearly universally exposed to pesticides, and these chemicals are often toxic to human health [1]. Billions of pounds of pesticides are applied worldwide on an annual basis, and pesticide poisoning is a common occurrence among agricultural workers [1]. Many commonly used pesticides, such as permethrin and the insect repellent N,N-diethyl-meta-toluamide, DEET, have been deemed safe and relatively benign by the United States Environmental Protection Agency [2, $3]$. However, recent research efforts have identified numerous toxicities and health effects resulting from exposure to these environmental chemicals [2, 4-6]. Initial concern regarding permethrin was low due to the fact that it is rapidly metabolized and excreted in urine [4]. However, bioaccumulation of permethrin in both adipose and brain tissue is cause for concern [4]. Permethrin has been established as a neurotoxin [5]. A mixture of DDT and permethrin results in disruption of homeostatic function in hepatocytes, and at high levels, results in inflammation and oxidative stress [6]. The benign status of commonly used pesticides is being challenged [7-9], but the regulatory agencies have not responded by updating guidelines and policies [2].

The toxicological effects of widely used pesticides on mammals are numerous [7]. A recent review [7] supported effects of oxidative stress and toxicity resulting from permethrin exposure. Reproductive malfunctions have also been shown in the offspring of mammals exposed to environmentally-relevant doses of permethrin in their drinking water [10]. The mixture of two common pesticides, permethrin and DEET, is proposed to have a synergistic effect on the health of exposed mammals, leading to enhanced neurotoxicity, increased mortality, and behavioral alterations [11]. This combination of these pesticides have also been suggested as a possible cause of Gulf War Illness (GWI) among humans [12]. Symptoms related to GWI, most significantly neurodegeration, have been observed in rodent models exposed to these pesticides [13-19]. An extensive review of the chronic exposure to pesticides experienced by humans shows increased risk of chronic diseases, reproductive abnormalities, and birth defects, which are all linked to genetic, epigenetic, and other biochemical alterations [12].

The exposure of human and animal populations to pesticide chemicals results in health problems in both the exposed individuals and in future generations [20]. A multigenerational exposure occurs on an individual and their germ line, and can also include exposure of a pregnant female and the developing fetus. The developing fetus is particularly susceptible to developmental perturbations which can be caused by exposure to environmental toxicants [21-23]. This is well established in animal populations, but recent investigation into human populations has shown the same phenomenon [12]. The developing fetus and infant are directly exposed to pesticides, which enter the placenta and are found in breast milk [21]. Decreased birth weight and length are found among minority women, a demographic known to experience more pesticide exposure [22]. In addition, there is an association among childhood leukemia incidence and parents who are occupationally exposed to pesticides, such as agricultural workers [23].

Epigenetic alterations, rather than de novo genetic alterations, are a likely mechanism of inheritance for these increased incidences of disease among mammalian and human populations $[24,25]$. The mechanisms of inheritance for the increased incidence of disease in the human populations likely involves epigenetic inheritance. Lind, et al [26]. demonstrate an association between persistent organic pollutants and DNA hypermethylation in the exposed individual. The direct exposure to pesticides is more prevalent among some populations, particularly agricultural laborers. Among such a population, increased methylation in or near 72 genes was found as a result of exposure to pesticides, mostly involving immune response genes [27]. Prenatal exposure to persistent pollutants yields hypomethylation in fetal blood [28]. Both hyper- and hypomethylation can have detrimental effects on gene expression, and this has greater impact early in development. Alterations in DNA methylation can also be passed on to future generations and lead to an increased incidence of disease [20, 29]. A large number of studies have demonstrated the cumulative effects of a wide variety of endocrine disrupting chemicals, prominent among them many pesticides. The longlasting effect of these exposures is proposed to persist through epigenetic alterations which include DNA methylation, histone alterations, and ncRNA modifications [30, 31]. These epigenetic alterations can impact the germline, so can be inherited in subsequent generations. An epigenetic transgenerational inheritance effect is established when an individual has experienced no direct exposure to a toxicant and still shows increased incidence of disease due to ancestral exposure [20]. The multigenerational and transgenerational inheritance of epigenetic alterations in response to exposure to toxicants such as pesticides increases the risk of disease in later generations. The lifelong and multigenerational effects of pesticide chemicals on the human population are numerous and include increased incidence of neurotoxicity [32]. Therefore, it is crucial to establish the extent of the effects caused by widely used pesticides such as permethrin and DEET.

Transgenerational inheritance of both epigenetic alterations and increased incidence of disease from the ancestral exposure to the pesticide mixture of permethrin and DEET have been demonstrated in rats [33]. A 
significant increase in total disease incidence, pubertal abnormalities, testis disease and ovarian disease was found in the F3 generation (transgenerational) of ancestrally exposed individuals [33]. Significant DNA methylation alterations were also observed in the sperm of the pesticide lineage animals compared to control animals [33]. Similar epigenetic transgenerational inheritance of sperm epigenetic alterations and associated increased disease incidence have been demonstrated as a result of ancestral exposure to the fungicide vinclozolin [34], the pesticide DDT [35] the herbicide glyphosate [36] and herbicide atrazine [37].

The association between altered epigenetics and increased disease incidence has been established in many species [20]. The epigenetic alterations induced by exposure to environmental toxicants is not only a mechanism for long-term multigenerational direct exposure effects, but also promote detrimental transgenerational health effects. The epigenetic alterations can potentially serve as biomarkers of the susceptibility of adverse health prospects for the directly exposed individuals and their progeny [20, 30]. Transgenerational epigenetic alterations associated with increased incidence of disease can possibly be used as biomarkers for ancestral exposure and disease [38] and have been established for multiple widespread and persistent environmental toxicants $[37,39,40]$. The current study was designed to investigate the incidence of disease and inherited differential methylation of DNA in the transgenerational F3 generation (great-grand offspring) of rats whose ancestors were exposed to the pesticide mixture of permethrin and DEET [33] in order to identify epigenetic biomarkers of differential DNA methylation regions (DMRs) for specific disease using an epigenome-wide association study (EWAS) approach.

\section{Methods}

\section{Animal studies and breeding}

As previously described [34, 41], female and male rats of an outbred strain Hsd:Sprague Dawley SD (Harlan) at 70 to 100 days of age were fed ad lib with a standard rat diet and ad lib tap water. Timed-pregnant females $(n=$ 4) were mated and on days 8 through 14 of gestation [42] were administered daily intraperitoneal injections of pesticides permethrin $(150 \mathrm{mg} / \mathrm{kg} \mathrm{BW} /$ day dissolved in

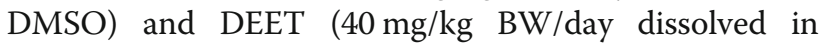
DMSO) (Chem Service, Westchester PA) or vehicle control dimethyl sulfoxide (DMSO), as previously described [38]. The transient exposure was during gestation at embryonic day 8-14 (E8-E14) associated with gonadal sex determination and epigenetic programming of the germline.

The gestating female rats treated were designated as the F0 generation. At each generation approximately 5 different litters were generated and culled to 10 pups to reduce litter bias. No sibling or cousin breeding was used to avoid inbreeding artifacts. The F1- F3 generation control and pesticide lineages were housed in the same room and racks with lighting, food and water as previously described [38, 42, 43]. Non-littermate females and males aged 70-100 days from the F1 generation of pesticides or control lineages were bred to others within their treatment group to obtain F2 generation offspring. Unrelated F2 generation rats were bred to obtain F3 generation offspring. Only the F0 generation received treatments. All experimental protocols for the procedures with rats were pre-approved by the Washington State University Animal Care and Use Committee (IACUC approval \# 2568). All methods were performed in accordance with the relevant guidelines and regulations. The sperm samples and tissue sections from the previous study [44] were archived and used for the current study with new histological and molecular analysis.

\section{Tissue harvest and histology processing}

As previously described [44], at 12 months of age, rats were euthanized by $\mathrm{CO}_{2}$ inhalation and cervical dislocation for tissue harvest. Testis, prostate, and kidney were fixed in Bouin's solution (Sigma) followed by $70 \%$ ethanol, then processed for paraffin embedding, and hematoxylin and eosin ( $\mathrm{H} \& \mathrm{E})$ staining by standard procedures for histopathological examination. Paraffin five microns sections were processed, stained, and processed by Nationwide Histology, Spokane WA, USA.

\section{Histopathology examination and disease classification}

Archived histology slides or paraffin blocks from the previous study [44] were used for a new histology analysis for the current study. Stained testis, prostate, and kidney slides were imaged through a microscope using $4 \mathrm{x}$ objective lenses (testis and prostate) or 10x objective lenses (kidney). Tiled images were captured using a digital camera. Tiled images for each tissue were photo-merged into a single image using Adobe Photoshop (ver. 21.1.2, Adobe, Inc.). Images were evaluated and pathology features digitally marked using Photoshop software. The Washington Animal Disease Diagnostic Laboratory (WADDL) at the Washington State University College of Veterinary Medicine has board certified veterinary pathologists, and assisted in initially establishing the criteria for the pathology analyses and identifying parameters to assess [45]. The tissues evaluated histologically were selected from previous literature showing them to have pathology in transgenerational models [29, 33, 37, 44, 46-50], with an emphasis on reproductive organs. Histopathology readers were trained to recognize the specific abnormalities evaluated for this study in rat testis, ventral prostate and kidney. Two individuals blinded to the exposure evaluated each 
tissue image for abnormalities. If there was disagreement about the disease status, then a third individual blinded to the exposure evaluated the tissue. Sets of quality control (QC) slides were generated for each tissue, and were read by each reader prior to evaluating any set of experimental slides. These QC slide results were monitored for reader accuracy and concordance.

As previously described [20], testis histopathology criteria included the presence of vacuoles in the seminiferous tubules, azoospermic atretic seminiferous tubules, and 'other' abnormalities including sloughed spermatogenic cells in center of the tubule and a lack of a tubule lumen. As previously described [51, 52], prostate histopathology criteria included the presence of vacuoles in the glandular epithelium, atrophic glandular epithelium and hyperplasia of prostatic gland epithelium. Kidney histopathology criteria included reduced size of glomerulus, thickened Bowman's capsule, and the presence of proteinaceous fluid-filled cysts $>50 \mu \mathrm{m}$ in diameter. A cutoff was established to declare a tissue 'diseased' based on the mean number of histopathological abnormalities plus two standard deviations from the mean of control group tissues, as assessed by each of the individual observers blinded to the treatment groups. This number (i.e. greater than two standard deviations) was used to classify rats into those with and without testis, prostate, or kidney disease in each lineage. A rat tissue section was finally declared 'diseased' only when at least two of the three observers marked the same tissue section 'diseased'. Onset of puberty was assessed in males starting at 35 days of age by the presence of balano-preputial separation. Obesity was assessed with an increase in body mass and a qualitative evaluation of abdominal adiposity, as previously described $[33,47,53-55]$. The statistical analyses for pathology results were expressed as the proportion of affected animals that exceeded a predetermined threshold (testis, prostate or kidney disease frequency, tumor frequency, obese frequency). Groups were analyzed using Fisher's exact test.

\section{Epididymal sperm collection and DNA isolation}

The protocol is described in detail in reference [44]. Briefly, the epididymis was dissected free of fat and connective tissue, then, after cutting open the cauda, placed into $6 \mathrm{ml}$ of phosphate buffer saline (PBS) for $20 \mathrm{~min}$ at room temperature. Further incubation at $4{ }^{\circ} \mathrm{C}$ will immobilize the sperm. The tissue was then minced, the released sperm pelleted at $4{ }^{\circ} \mathrm{C} 3000 \mathrm{x} g$ for $10 \mathrm{~min}$, then resuspended in NIM buffer and stored at $-80^{\circ} \mathrm{C}$ for further processing. An appropriate amount of rat sperm suspension was used for DNA extraction. Previous studies have shown mammalian sperm heads are resistant to sonication unlike somatic cells [56, 57]. Somatic cells and debris were therefore removed by brief sonication
(Fisher Sonic Dismembrator, model 300, power 25), then centrifugation and washing 1-2 times in $1 \mathrm{X}$ PBS. The resulting pellet was resuspended in $820 \mu \mathrm{L}$ DNA extraction buffer and $80 \mu \mathrm{l} 0.1 \mathrm{M}$ DTT added, then incubated at $65^{\circ} \mathrm{C}$ for $15 \mathrm{~min}$. Eighty microliter proteinase $\mathrm{K}(20$ $\mathrm{mg} / \mathrm{ml}$ ) was added and the sample was incubated at $55^{\circ} \mathrm{C}$ for $2-3 \mathrm{~h}$ under constant rotation. Protein was removed by addition of protein precipitation solution (300 $\mu$ l, Promega A795A), incubation for $15 \mathrm{~min}$ on ice, then centrifugation at $13,500 \mathrm{rpm}$ for $30 \mathrm{~min}$ at $4{ }^{\circ} \mathrm{C}$. One $\mathrm{ml}$ of the supernatant was precipitated with $2 \mu \mathrm{l}$ of Glycoblue (Invitrogen, AM9516) and $1 \mathrm{ml}$ of cold 100\% isopropanol. After incubation, the sample was spun at $13,500 \times g$ for $30 \mathrm{~min}$ at $4{ }^{\circ} \mathrm{C}$, then washed with $70 \%$ cold ethanol. The pellet was air-dried for about $5 \mathrm{~min}$ then resuspended in $100 \mu \mathrm{l}$ of nuclease free water.

\section{Methylated DNA Immunoprecipitation (MeDIP)}

The archived sperm samples were prepped as previously described [44]. Genomic DNA was sonicated and run on $1.5 \%$ agarose gel for fragment size verification. The sonicated DNA was then diluted with $1 \mathrm{X}$ TE buffer to $400 \mu \mathrm{l}$, then heat-denatured for $10 \mathrm{~min}$ at $95^{\circ} \mathrm{C}$, and immediately cooled on ice for $10 \mathrm{~min}$ to create singlestranded DNA fragments. Then $100 \mu \mathrm{l}$ of 5X IP buffer and $5 \mu \mathrm{g}$ of antibody (monoclonal mouse anti 5-methyl cytidine; Diagenode \#C15200006) were added, and the mixture was incubated overnight on a rotator at $4{ }^{\circ} \mathrm{C}$. The following day magnetic beads (Dynabeads M280 Sheep anti-Mouse IgG; Life Technologies 11201D) were pre-washed per manufacturer's instructions, and $50 \mu \mathrm{l}$ of beads were added to the $500 \mu \mathrm{l}$ of DNA-antibody mixture from the overnight incubation, then incubated for $2 \mathrm{~h}$ on a rotator at $4{ }^{\circ} \mathrm{C}$. After this incubation, the samples were washed three times with $1 \mathrm{X}$ IP buffer using a magnetic rack. The washed samples were then resuspended in $250 \mu \mathrm{l}$ digestion buffer $(5 \mathrm{mM}$ Tris $\mathrm{PH} 8$, 10.mM EDTA, 0.5\% SDS) with $3.5 \mu$ l Proteinase K $(20$ $\mathrm{mg} / \mathrm{ml}$ ), and incubated for $2-3 \mathrm{~h}$ on a rotator at $55^{\circ} \mathrm{C}$. DNA clean-up was performed using a PhenolChloroform-Isoamyl-Alcohol extraction, and the supernatant precipitated with $2 \mu \mathrm{l}$ of Glycoblue $(20 \mathrm{mg} / \mathrm{ml})$, $20 \mu \mathrm{l}$ of $5 \mathrm{M} \mathrm{NaCl}$ and $500 \mu \mathrm{l}$ ethanol in $-20^{\circ} \mathrm{C}$ freezer for one to several hours. The DNA precipitate was pelleted, washed with $70 \%$ ethanol, then dried and resuspended in $20 \mu \mathrm{l} \mathrm{H}_{2} \mathrm{O}$ or $1 \mathrm{X}$ TE. DNA concentration was measured in Qubit (Life Technologies) with the ssDNA kit (Molecular Probes Q10212).

\section{MeDIP-Seq analysis}

As previously described [31], MeDIP DNA was used to create libraries for next generation sequencing (NGS) using the NEBNext Ultra RNA Library Prep Kit for Illumina (San Diego, CA) starting at step 1.4 of the 
manufacturer's protocol to generate double stranded DNA from the single-stranded DNA resulting from MeDIP. After this step, the manufacturer's protocol was followed indexing each sample individually with NEBNext Multiplex Oligos for Illumina. The WSU Spokane Genomics Core sequenced the samples on the Illumina HiSeq 2500 at PE50, with a read size of approximately $50 \mathrm{bp}$ and approximately $10-20$ million reads per pool. Twelve libraries were run in one lane.

\section{Statistics and bioinformatics}

The DMR identification and annotation methods follow those presented in previous published papers [31, 37]. Data quality was assessed using the FastQC program (https://www.bioinformatics.babraham.ac.uk/projects/fastqc/). The data was cleaned and filtered to remove adapters and low-quality bases using Trimmomatic [58]. The reads for each MeDIP sample were mapped to the Rnor 6.0 rat genome using Bowtie2 [59] with default parameter options. The mapped read files were then converted to sorted BAM files using SAMtools [60]. The MEDIPS R package [61] was used to calculate differential coverage between disease and non-disease sample groups. The edgeR $p$-value [62] was used to determine the relative difference between the two groups for each genomic window. Windows with an edgeR $p$-value less than an arbitrarily selected threshold were considered DMR. The site edges were extended until no genomic window with an edgeR p-value less than 0.1 remained within $1000 \mathrm{bp}$ of the DMR. The edgeR p-value was used to assess the significance of the DMR identified. A false discovery rate (FDR) analysis for each comparison was performed and provided a $p<0.05$ for the multiple disease DMRs and a $p<0.1$ for 162 kidney disease DMRs. The remaining analysis had an FDR $p>0.1$. Due to the lower number of individuals with one specific disease type, an FDR analysis was generally not useful, nor was a permutation analysis, for the specific disease biomarkers [63-68]. Differential epimutation sites were annotated using the biomaRt $R$ package [69] to access the Ensembl database [70]. The DMR associated genes were then automatically sorted into functional groups using information provided by the DAVID [71] and Panther [72] databases incorporated into an internal curated database (www.skinner.wsu.edu under genomic data). A Pathway Studio, Elsevier, database and network tool was used to assess physiological and disease process gene correlations. All molecular data has been deposited into the public database at NCBI (GEO \# GSE158254) and R code computational tools available at GitHub (https://github.com/ skinnerlab/MeDIP-seq) and www.skinner.wsu.edu.

\section{Results}

As previously described [33], outbred Sprague Dawley gestating female rats (F0 generation) received a transient exposure during the developmental period of fetal gonadal sex determination to permethrin $(150 \mathrm{mg} / \mathrm{kg}$ bodyweight/day) and DEET ( $40 \mathrm{mg} / \mathrm{kg}$ bodyweight/day). The no observable adverse effect level (NOAEL) for long-term exposure to permethrin in rats ranges from 100 to $500 \mathrm{mg} / \mathrm{kg} /$ day, while there has been no lowest observable adverse effect level established in humans [reviewed in [73]]. The NOAEL for exposure to DEET is $200 \mathrm{mg} / \mathrm{kg} /$ day [13]. These relatively low doses, that are below the NOAEL, were administered during embryonic days 8-14 (E8-E14) at the time of fetal gonadal sex determination. The F1 generation offspring were directly exposed as a fetus, and F2 generation grand-offspring exposed as the germline in the F1 generation. These were each bred at 90 days of age within the exposure lineage. Approximately five litters were generated at each generation with no sibling or cousin breeding to avoid any inbreeding artifacts [33]. The F3 generation great-grand-offspring is required to establish the transgenerational inheritance generation of ancestral exposure. A control lineage was established that used F0 gestating rats exposed to the vehicle control dimethyl sulfoxide (DMSO). The archived sperm samples and histology paraffin blocks from the initial study [33] were reanalyzed for the current study. Disease pathology was evaluated in pesticide exposure and control lineages at 1 year of age. The pesticides exposure lineage transgenerational individuals with specific disease or pathology were grouped as representatives of the pathology exhibited. The remaining individuals with no disease were grouped as "no disease." Comparisons between these two groups were made for analysis of sperm DNA methylation (i.e. methylome). The differential DNA methylation regions (DMRs) in sperm used a methylated DNA immunoprecipitation (MeDIP) followed by next generation sequencing (Seq) of an MeDIP-Seq analysis for an EWAS approach for the identification of specific disease associated epigenetic biomarkers.

As previously described [33] in the Methods, pathology analysis was assessed by examining sections of male testis, kidney, and prostate. The new histological sections obtained from archived paraffin blocks and slides [33] were captured and analyzed digitally for greater accuracy. The digital images were analyzed by two different observers blinded to the exposure. When discrepancies arose, a third counter blinded to the exposure analyzed the histological section. The raw count of abnormalities was obtained from each digital image. The pixel area was also determined from each image, allowing for a size correction between individual organ samples in the study. The final counts used for the analysis represent the number of abnormalities seen per $\mathrm{mm}^{2}$ for each individual image. The pathology parameters identified are as previously described in the Methods [33]. In brief, each counter records the incidence of abnormalities in each tissue. In testis, atrophy 
Table 1 F3 generation pesticides lineage males pathology. The individual animals for the pesticides lineage males are listed and a (+) indicates presence of disease and (-) absence of disease. The shaded disease identifies those animals used for that disease molecular analysis. The number of animals with disease versus total number of animals and percentage is presented. The comparison no disease animals are indicated with a (0)

\begin{tabular}{|c|c|c|c|c|c|c|c|c|}
\hline Molecular ID & Late Puberty & Testis & Prostate & Kidney & Obesity & Tumor & Multiple Disease & Total Disease \\
\hline$\overline{\mathrm{PS} 1}$ & - & - & - & - & - & - & - & 0 \\
\hline PS2 & - & - & - & - & - & - & - & 0 \\
\hline PS3 & - & + & - & - & - & - & - & 1 \\
\hline PS4 & - & + & - & - & - & - & - & 1 \\
\hline PS5 & - & - & - & - & - & - & - & 0 \\
\hline PS6 & - & - & - & - & - & - & - & 0 \\
\hline PS7 & - & - & - & - & - & - & - & 0 \\
\hline PS8 & - & - & - & - & - & - & - & 0 \\
\hline PS9 & - & + & - & - & - & - & - & 1 \\
\hline PS10 & - & - & - & - & - & - & - & 0 \\
\hline PS11 & - & - & - & - & - & - & - & 0 \\
\hline PS12 & - & - & - & - & - & - & - & 0 \\
\hline PS13 & - & - & - & - & - & - & - & 0 \\
\hline PS14 & - & + & - & + & - & - & + & 2 \\
\hline PS15 & - & - & - & - & - & - & - & 0 \\
\hline PS16 & - & - & - & + & - & - & - & 1 \\
\hline PS17 & - & $\mathrm{n} / \mathrm{a}$ & + & - & - & - & - & 1 \\
\hline PS18 & - & - & - & - & - & - & - & 0 \\
\hline PS19 & - & - & + & - & - & - & - & 1 \\
\hline PS20 & - & + & + & + & + & - & + & 4 \\
\hline PS21 & - & - & - & - & - & - & - & 0 \\
\hline PS22 & - & + & + & - & - & - & + & 2 \\
\hline PS23 & - & - & - & + & - & - & - & 1 \\
\hline PS24 & - & - & - & - & - & - & - & 0 \\
\hline PS25 & - & - & - & + & - & - & - & 1 \\
\hline PS26 & - & - & + & - & - & - & - & 1 \\
\hline PS27 & + & + & - & + & + & - & + & 4 \\
\hline PS28 & - & - & - & + & - & - & - & 1 \\
\hline PS29 & - & + & - & - & + & - & + & 2 \\
\hline PS30 & - & + & - & + & - & - & + & 2 \\
\hline PS31 & - & - & - & + & - & - & - & 1 \\
\hline PS32 & + & + & - & - & - & - & + & 2 \\
\hline PS33 & + & - & - & - & - & - & - & 1 \\
\hline PS34 & + & - & - & + & - & - & + & 2 \\
\hline PS35 & $\mathrm{n} / \mathrm{a}$ & + & + & - & - & - & + & 2 \\
\hline PS36 & $\mathrm{n} / \mathrm{a}$ & + & - & + & - & - & + & 2 \\
\hline PS37 & $\mathrm{n} / \mathrm{a}$ & + & + & + & - & - & + & 3 \\
\hline PS38 & $\mathrm{n} / \mathrm{a}$ & + & - & + & - & - & + & 2 \\
\hline PS39 & - & - & - & - & - & + & - & 1 \\
\hline PS40 & - & - & + & - & - & - & - & 1 \\
\hline PS41 & - & - & - & + & - & - & - & 1 \\
\hline Totals & $4 / 37=11 \%$ & $14 / 40=35 \%$ & $8 / 41=20 \%$ & $14 / 41=34 \%$ & $3 / 41=7 \%$ & $1 / 41=2 \%$ & $12 / 41=29 \%$ & \\
\hline
\end{tabular}


of a seminiferous tubule, the arrest of maturation of sperm (indicated by sloughed cells in the center of the tubule), and the presence of vacuoles were indicated disease pathologies. The abnormalities counted in kidney include a reduction in size of glomeruli, a thickening of the Bowman's capsule, and the presence of cysts. Prostate abnormalities counted included atrophy of the epithelial cells, hyperplasia in the epithelial layer, and the presence of vacuoles within the epithelial layer of the prostatic glands. Obese and lean phenotypes were assigned following assessment of body and abdominal adiposity. The individual F3 generation animals are listed as $(+)$ which indicates presence of disease or $(-)$ the absence of disease for the current F3 generation pesticide lineage male pathology (Table 1). Only those individuals with a single disease for a specific pathology were used for that pathology molecular analysis to avoid any comorbidity effects and variables in the analysis. Animals exhibiting more than one disease are all listed under the category "Multiple Disease." Those animals used in the molecular analysis are indicated by gray highlights in Table 1. Due to low prevalence of disease in the control animal groups, control lineage animals were not used in the identification of epigenetic biomarkers.

The experimental design was focused on the identification of transgenerational DMRs in sperm. Sperm collected and archived from the pesticide lineage F3 generation males [33] were used for epigenetic analysis. DNA from the sperm was isolated and fragmented with sonication, as described in the Methods. The methylated
DNA immunoprecipitation (MeDIP) using a methylcytosine antibody was used to identify alterations in DNA methylation. The methylated DNA fragments were then sequenced for an MeDIP-Seq analysis, as described in the Methods [34, 40]. The differential DNA methylation regions (DMRs) were identified between the disease versus non-disease within the pesticides lineage animals (Fig. 1). The transgenerational sperm DMR numbers are presented in Fig. 1 for different edgeR statistical $p$-value cutoff thresholds, and $p<1 \mathrm{e}-04$ (diseased versus nondiseased) for the pesticide lineage were selected as the threshold for subsequent analyses. Disease-specific DMRs were identified among the pesticides treated animals as shown in Table 1 . The pesticides lineage animals disease included prostate disease, kidney disease, testis disease and multiple diseases (Fig. 1a-d). The all windows column represents all DMR windows, and multiple window column includes those with neighboring $1 \mathrm{~kb}$ sites. Only kidney disease and multiple disease DMRs had multiple adjacent sites. In the current analysis, 1000 bp windows were used in the identification of DMRs.

The previous reported control versus exposure disease associated DMRs [33] were a result of pooled sample analyses, so it was not feasible to identify individual sites as epigenetic biomarkers for disease. In the current study, the MeDIP-seq analysis was performed on individual animal samples allowing for the identification of specific epigenetic biomarkers shared among all pesticide lineage animals with a specific disease. Analysis revealed 463 DMRs associated with kidney disease among

DMR Identification

A Prostate Disease DMR Biomarkers

\begin{tabular}{ccc}
\hline $\mathrm{p}$-value & All Window & Multiple Window \\
\hline 0.001 & 1278 & 1 \\
$\mathbf{1 e}-\mathbf{0 4}$ & $\mathbf{2 1 8}$ & $\mathbf{0}$ \\
$1 \mathrm{e}-05$ & 22 & 0 \\
$1 \mathrm{e}-06$ & 2 & 0 \\
$\mathrm{e}-07$ & 0 & 0 \\
\hline \hline \multicolumn{2}{c}{ Significant windows } & 1 \\
Number of DMR & 218 \\
\hline
\end{tabular}

C Testis Disease DMR Biomarkers

\begin{tabular}{ccc}
\hline$p$-value & All Window & Multiple Window \\
\hline 0.001 & 983 & 2 \\
$1 \mathrm{e}-04$ & 163 & 0 \\
$1 \mathrm{e}-05$ & 35 & 0 \\
$1 \mathrm{e}-06$ & 7 & 0 \\
$1 \mathrm{e}-07$ & 2 & 0 \\
\hline \hline \multicolumn{2}{r}{ Significant windows } & 1 \\
Number of DMR & 163 \\
\hline
\end{tabular}

B Kidney Disease DMR Biomarkers

\begin{tabular}{|c|c|c|}
\hline p-value & All Window & Multiple Window \\
\hline 0.001 & 2339 & 13 \\
\hline 1e-04 & 463 & 4 \\
\hline 1e-05 & 96 & 0 \\
\hline 1e-06 & 25 & 0 \\
\hline $1 \mathrm{e}-07$ & 6 & 0 \\
\hline \multicolumn{2}{|c|}{ Significant windows } & 2 \\
\hline \multicolumn{2}{|c|}{ Number of DMR } & 459 \\
\hline
\end{tabular}

D Multiple Disease DMR Biomarkers

\begin{tabular}{|c|c|c|c|c|}
\hline$p$-value & All Window & & \multicolumn{2}{|c|}{ Multiple Window } \\
\hline 0.001 & 7595 & & \multicolumn{2}{|c|}{194} \\
\hline 1e-04 & 2100 & & \multicolumn{2}{|c|}{37} \\
\hline $1 e-05$ & 597 & & \multicolumn{2}{|c|}{9} \\
\hline 1e-06 & 178 & & \multicolumn{2}{|c|}{3} \\
\hline $1 e-07$ & 55 & & \multicolumn{2}{|c|}{1} \\
\hline Significa & indows & 1 & 2 & 3 \\
\hline Numbe & DMR & 2063 & 32 & 5 \\
\hline
\end{tabular}

Fig. 1 DMR identification and numbers. The number of DMRs found using different p-value cutoff thresholds. The All Window column shows all DMRs. The Multiple Window column shows the number of DMRs containing at least two significant windows (1000 bp each). The number of DMRs with the number of significant windows (1000 bp per window) at a $p$-value threshold of $p<1 \mathrm{e}-04$ for DMR is presented. a Prostate disease DMRs; b Kidney disease DMRs; c Testes disease DMRs; and $\mathbf{d}$ Multiple disease DMRs 
which 197 (43\%) show an increase in DNA methylation. There were 218 DMRs associated with prostate disease and $102(47 \%)$ show an increase in DNA methylation. There were 163 DMRs associated with testis disease and $52(32 \%)$ show an increase in DNA methylation. The multiple disease group showed 2100 unique DMRs that have 1045 (50\%) with an increase in DNA methylation. The specific disease DMR lists and log-fold change information are presented in Supplemental Tables S1-S4.

Chromosomal locations of the disease associated DMRs are shown in Fig. 2. DMRs are represented as arrowheads and DMR clusters are represented by black boxes. DMRs are present for each individual disease on all chromosomes, except the $\mathrm{Y}$ chromosome and mitochondrial DNA (MT). Interestingly, the multiple disease signatures are present on the $\mathrm{Y}$ chromosome, as well as all other chromosomes. These results support the idea that the transgenerational epigenetic effects of ancestral pesticides exposure are genome-wide. Genomic features are shown in Fig. 3. The CpG density of DMRs is low, 1-3 CpG/100 bp, and DMR length for most disease associations is between 1 and 3 kilobases. The principal component analyses (PCA) of the RPKM adjusted read depths at differential DMR sites for each sample are
DMR Chromosomal Locations

A DMR Prostate Disease Biomarker

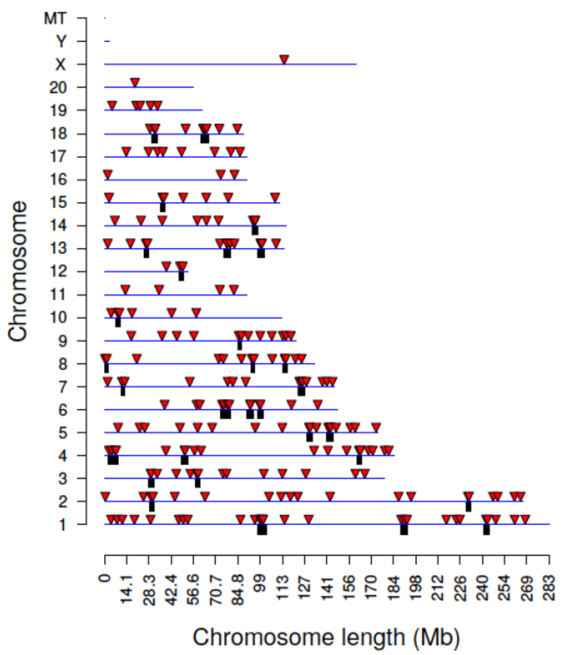

C DMR Testis Disease Biomarker

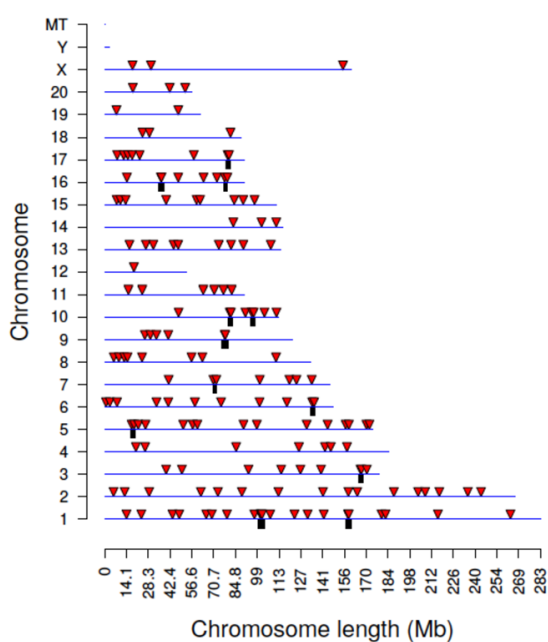

B DMR Kidney Disease Biomarker

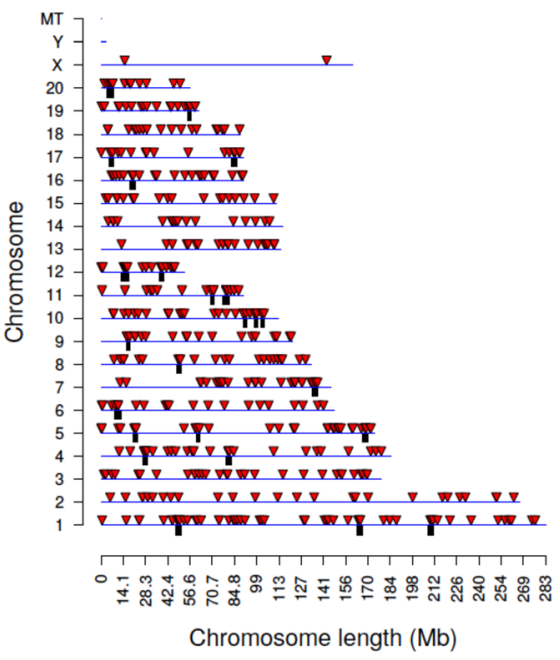

D DMR Multiple Disease Biomarker

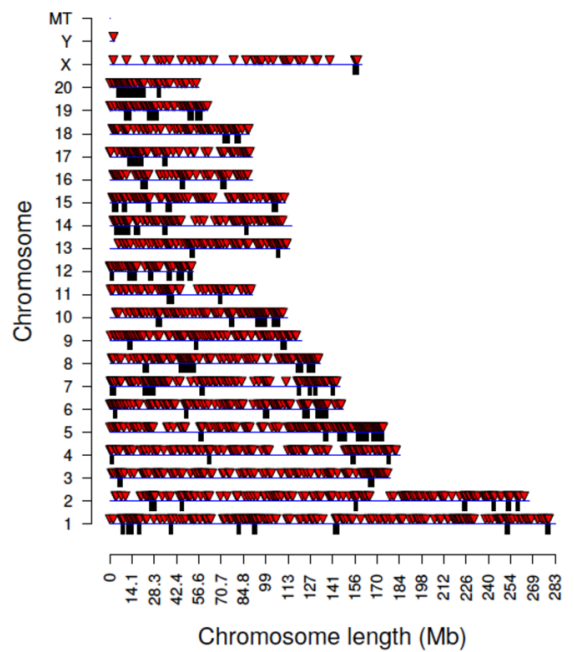

Fig. 2 DMR chromosomal locations. The DMR locations on the individual chromosomes is represented with an arrowhead and a cluster of DMRs with a black box. All DMRs containing at least one significant window at a p-value threshold of 1e-04 for DMR are shown. a Prostate disease DMRs; b Kidney disease DMRs; c Testes disease DMRs; and $\mathbf{d}$ Multiple disease DMRs 
DMR Genomic Features
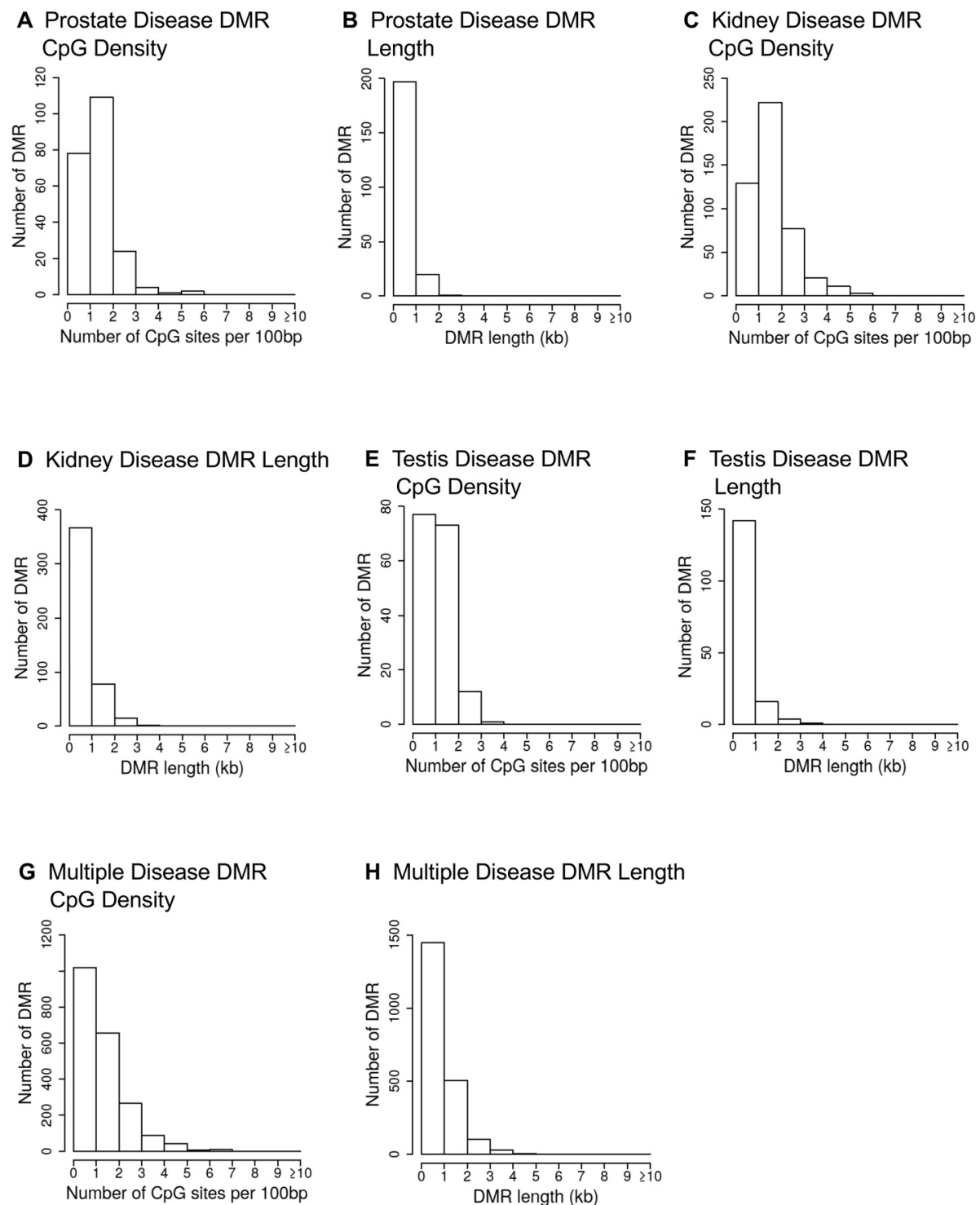

H Multiple Disease DMR Length

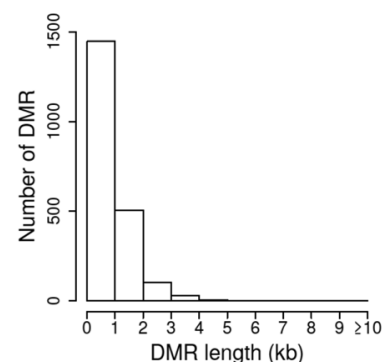

Fig. 3 DMR genomic features. The number of DMRs at different CpG densities and length (kb). All DMRs at a p-value threshold of 1e-04 are shown. a Prostate disease DMR CpG density; b Prostate disease DMR length; c Kidney disease DMR CpG density; d Kidney disease DMR length; e Testes disease DMR CpG density; f Testes disease DMR length; $\mathbf{g}$ Multiple disease DMR CpG density; and $\mathbf{h}$ Multiple disease DMR length

shown in Fig. 4. The PCA plots show how the samples cluster according to disease compared to non-disease when DMR sites are considered (Fig. 4).

An overlap analysis of the different disease specific sperm DMRs is presented in Fig. 5. A Venn diagram overlap of the different disease DMRs at $p<1 \mathrm{e}-04 \mathrm{dem}$ onstrates no DMRs in common and the majority of DMRs are disease specific, Fig. 5a. An extended overlap of the disease associated DMRs $(p<1 \mathrm{e}-04)$, with each disease DMR set at a reduced significance level of $p<$ 0.05 (Fig. 5b), shows 34\% overlap between kidney disease and prostate disease DMRs. There is higher overlap between individual diseases and the multiple disease category, with $49 \%$ overlap between prostate and multiple disease and 58\% overlap between kidney disease and multiple disease. This is anticipated as the multiple disease category includes individuals with several of the individual diseases.

Potential common DMRs among all the different disease specific DMRs was investigated. The overlap was determined at a statistical threshold of DMRs at $\mathrm{p}<0.05$, Fig. 5c. As expected, the total number of DMRs increase and 225 DMR were found to be in common between the testis, kidney, prostate, and multiple disease DMRs. A 
A Prostate disease DMR biomarkers

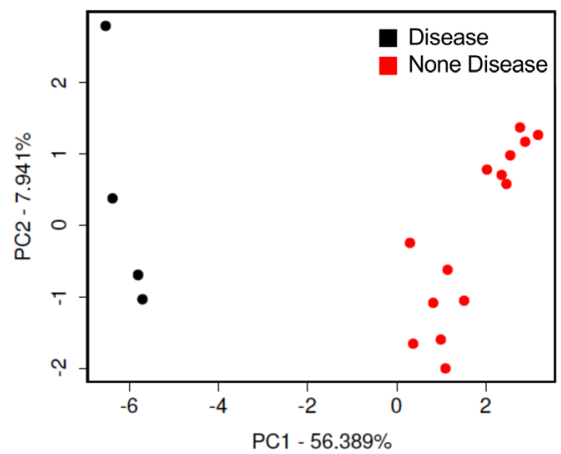

C Testis disease DMR biomarkers

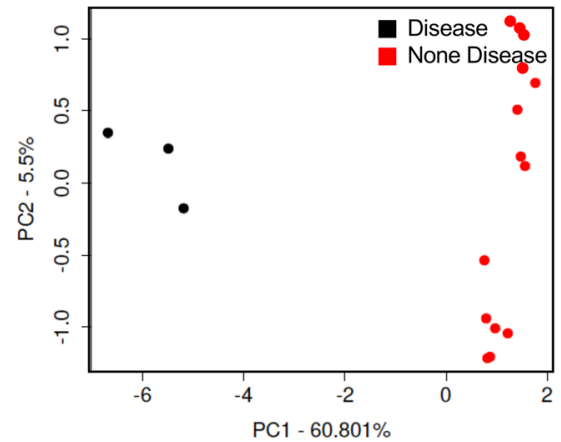

B Kidney disease DMR biomarkers

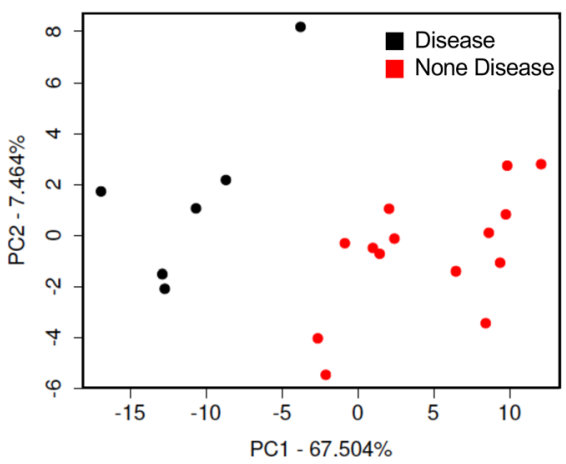

D Multiple disease DMR biomarkers

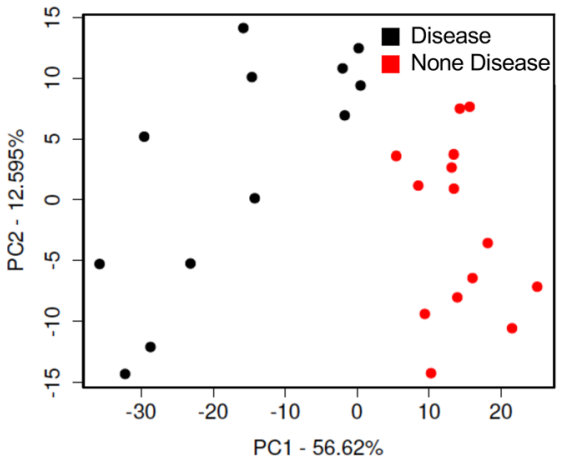

Fig. 4 DMR principal component analysis. The first two principal components used. The underlying data is the RPKM read depth for DMR genomic windows. a Prostate disease DMRs PCA; b Kidney disease DMRs PCA; c Testes disease DMRs PCA; and $\mathbf{d}$ Multiple disease DMRs PCA

Venn diagram of the disease specific DMRs at $p<1 \mathrm{e}-04$ and those overlapping 225 DMR at $p<0.05$ demonstrated no common DMR among all the diseases, Fig. $5 \mathrm{~d}$. The highest overlap was with individual comparisons and the multiple disease, but none common with all. Observations indicate that the DMRs are predominantly disease specific with no common set of DMRs, Fig. 5.

The disease specific DMR epimutation gene associations were identified and presented in Supplemental Tables S1-S4. Approximately 50\% of the DMRs had gene associations for each disease set of DMRs. The gene associations were sorted with functional gene categories and presented in Fig. 6a. The signaling, transcriptional, and metabolism were predominant. The pattern of DMR associated gene categories was similar for all the disease specific epimutations. The DMR associated gene pathways were identified through a KEGG pathway analysis, as described in the Methods. The top five pathways with associated genes are presented in Fig. 6b. The number of DMR associated genes within the pathway are presented in brackets for each disease. The metabolism, pathways in cancer and various signaling pathways were common to all the diseases.

The final analysis correlated the disease specific DMR associated genes with previously identified disease linked genes. A Pathway Studio gene network was used, as described in the Methods. Interestingly, the prostate, kidney and testis disease associated genes had correlations with each of the specific diseases, Fig. 7. The prostate disease DMR associated genes had links with subfertility and prostatic disease, Fig. 7a. The kidney disease DMR associated genes had links with kidney disease, chronic renal failure, and polycystic kidney disease, among others Fig. 7b. The testis disease DMR associated genes had links with infertility, Fig. 7c. The multiple disease DMR associated genes had links with all the various diseases, Fig. 8.

\section{Discussion}

Pesticides exposure is nearly ubiquitous in the human population [1, 12, 74, 75]. Many pesticide chemicals in common use are associated with abnormalities in reproduction, development, the nervous system, and overall health $[12,74,75]$. The detrimental effects of exposure to pesticides occur not only among the individuals directly exposed, but can have transgenerational detrimental health effects in subsequent generations [33]. Direct exposure impacts an individual and their germ line [20]. If the germline epigenetics is modified, then the offspring generated with the affected germ cell 


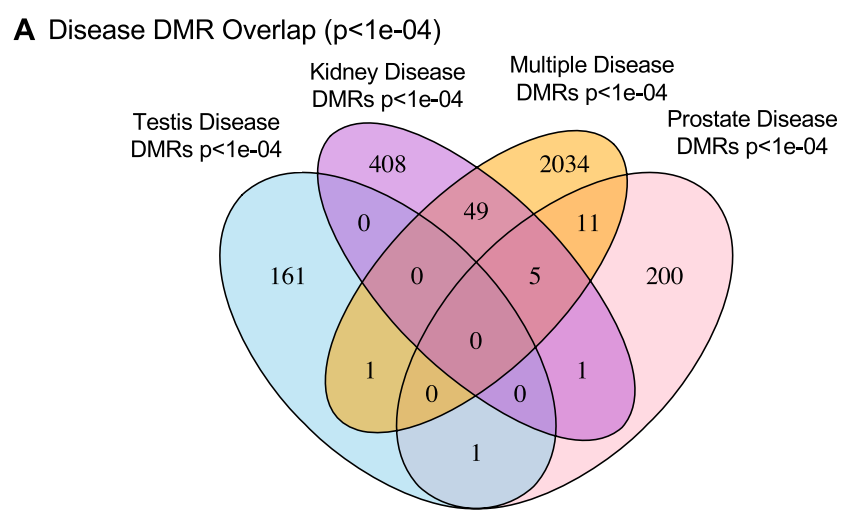

B Extended Overlap Disease DMRs

\begin{tabular}{|l|c|c|c|c|}
\hline p<1e-04 p<0.05 & $\begin{array}{c}\text { DMR } \\
\text { Prostate } \\
\text { Disease }\end{array}$ & $\begin{array}{c}\text { DMR } \\
\text { Kidney } \\
\text { Disease }\end{array}$ & $\begin{array}{c}\text { DMR } \\
\text { Testis } \\
\text { Disease }\end{array}$ & $\begin{array}{c}\text { DMR } \\
\text { Multiple } \\
\text { Disease }\end{array}$ \\
\hline DMR Prostate Disease & $218(100.0 \%)$ & $75(34.4 \%)$ & $19(8.7 \%)$ & $108(49.5 \%)$ \\
\hline DMR Kidney Disease & $115(24.8 \%)$ & $463(100.0 \%)$ & $32(6.9 \%)$ & $268(57.9 \%)$ \\
\hline DMR Testis Disease & $27(16.6 \%)$ & $22(13.5 \%)$ & $163(100.0 \%)$ & $37(22.7 \%)$ \\
\hline DMR Multiple Disease & $511(24.3 \%)$ & $868(41.3 \%)$ & $165(7.9 \%)$ & $2100(100.0 \%)$ \\
\hline
\end{tabular}

C Common DMR Overlap $p<0.05$

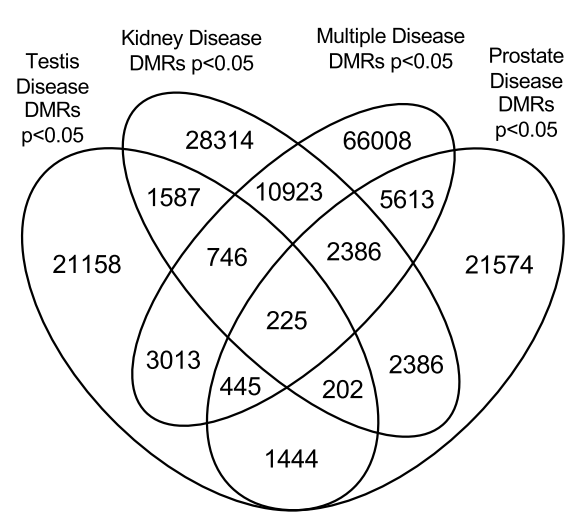

D Overlap DMRs

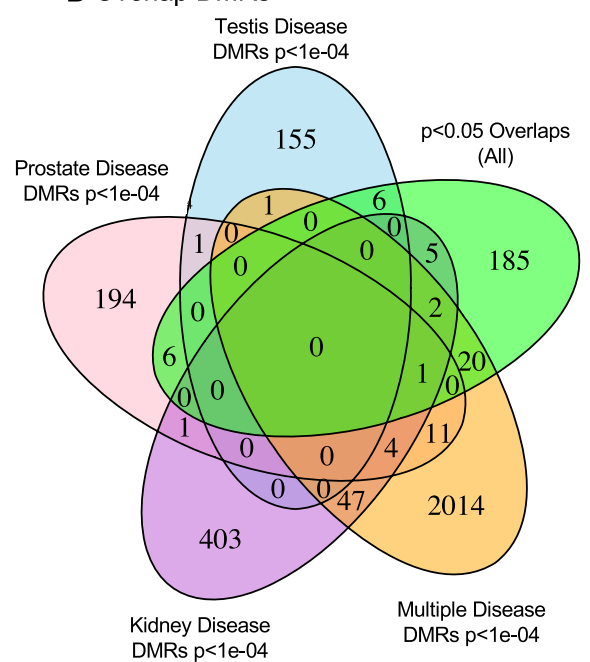

Fig. 5 Disease DMR Overlap. a Venn diagram overlap of disease DMRs at $p<1 \mathrm{e}-04$. $\mathbf{b}$ Extended overlap disease DMRs. The $\mathrm{p}$-value data set at $p<1 \mathrm{e}-04$ is compared to the $p<0.05$ data to identify potential overlap between the different pathologies with DMR number and percentage of the total presented. The gray highlight is the expected 100\% overlap. c Venn diagram overlap of disease DMRs at $p<0.05$ to identify the 225 overlapping DMRs. $\mathbf{d}$ Venn diagram overlap of disease DMRs at $p<1$ e-04 and combined overlap 225 DMRs at $p<0.05$

can have epigenetic impacts on health and physiology. Epigenetic transgenerational inheritance occurs when future generations in the absence of exposure also exhibit alterations and increased disease incidence [20]. The molecular mechanisms for epigenetic transgenerational inheritance involve an environmental perturbation that induces germline epigenetic alterations in the DNA methylation pattern, histone modifications, and altered ncRNA expression [31, 35]. Each of these mechanisms has been associated with transgenerational exposure to environmental toxicants and increased incidence of disease $[20,31,35]$. Both the ubiquity of pesticide applications and the extent of their detrimental health effects demand careful examination of the use and regulation of these chemicals. The current study was designed to use the F3 generation males for association of sperm epigenetic alterations with specific diseases resulting from an ancestral exposure to commonly used pesticides. The objective was to potentially identify disease specific biomarkers for the associated disease susceptibility.

The combination of the pesticides permethrin and the insect repellant $\mathrm{N}, \mathrm{N}$-diethyl-meta-toluamide, DEET is 


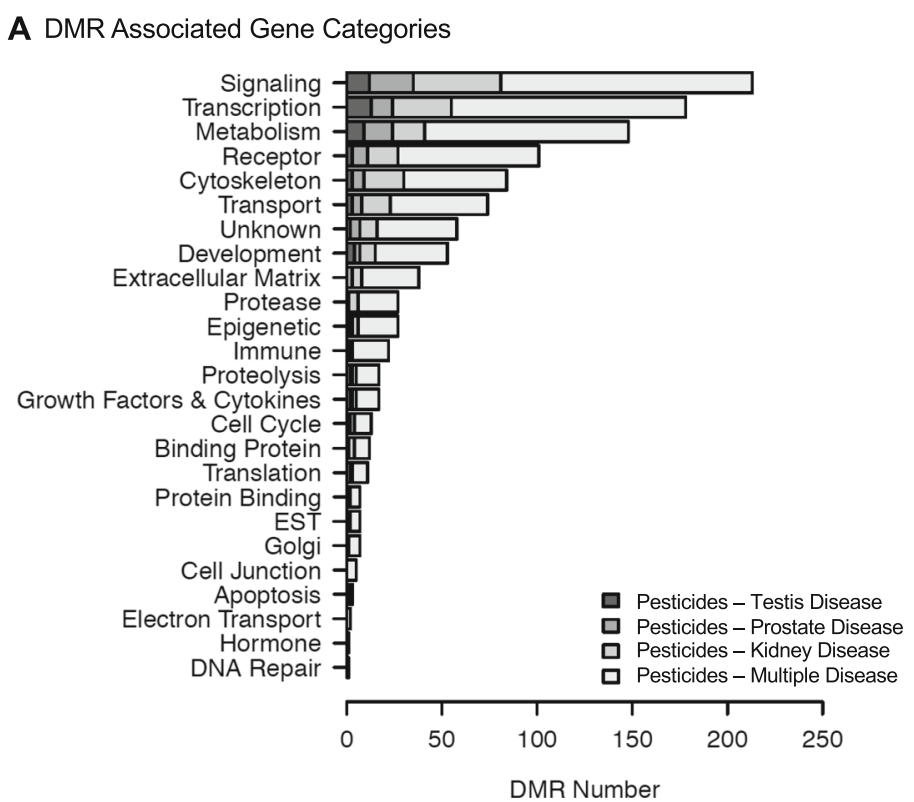

B DMR Associated Gene Pathways

Prostate Disease $p<1 e-04$ rno01100 Metabolic pathways (10) rno05200 Pathways in cancer (7) rno04510 Focal adhesion (6) rno05165 Human papillomavirus infection (6) rno04151 PI3K-Akt signaling pathway (6)

\section{Kidney Disease $p<1 e-04$} rno05200 Pathways in cancer (13) rno05165 Human papillomavirus infection (12) rno04151 PI3K-Akt signaling pathway (12) rno01100 Metabolic pathways (10) rno05169 Epstein-Barr virus infection (8)
Testis Disease $\mathrm{p}<1 \mathrm{e}-04$

rno05202 Transcriptional misregulation in cancer (5) rno04979 Cholesterol metabolism (4) rno01100 Metabolic pathways (4) rno05200 Pathways in cancer (2) rno04976 Bile secretion (2)

\section{Multiple Disease $p<1 e-04$} rno01100 Metabolic pathways (84)

rno05200 Pathways in cancer (29) rno04010 MAPK signaling pathway (28) rno04144 Endocytosis (23) rno04360 Axon guidance (23)

Fig. 6 DMR associated gene categories and pathways. a DMR associated gene categories. The gene categories and number of associated genes are presented for each disease group. $\mathbf{b}$ DMR associated gene pathways for each disease at $p<1 \mathrm{e}-04$ with top five KEGG pathways listed and number of associated genes in brackets

commonly used in homes and public places. There are numerous health effects associated with direct exposure to permethrin and DEET, including increased neurotoxity, reduced skeletal muscle function and behavior alterations in mammals [1, 2, 4-7, 10-19]. Exposure to this specific pesticides combination (below or near the previously established NOAEL) has been linked to epigenetic transgenerational inheritance of epigenetic alterations in sperm and associated increased incidence of disease [33]. The current study extends this analysis to identify epigenetic biomarkers associated with transgenerational incidence of specific diseases resulting from ancestral exposure to the pesticide mixture. The pathologies examined are relevant to human populations including prostate, testis and kidney disease, as well as multiple disease incidence in individuals, similar to the pattern of Gulf War Illness (GWI), which has been linked to exposure to organophosphate pesticide chemicals [13-19].
The negative health effects of pesticides exposure do not stop with the individuals directly exposed but are shown to occur transgenerationally in subsequent generations $[20,30]$. The identification of epigenetic biomarkers can be potentially used for determining later life health effects and health effects on future generations.

Epigenetic alterations are more common among individuals with disease $[34,37,40,41]$ than specific genetic alterations or mutations, which often appear in a very small percentage of individuals with the associated disease. The current study examined differential DNA methylation regions (DMRs) between specific diseased and non-diseased individuals whose great-grandparents were exposed to the pesticides mixture. Several hundred transgenerational epigenetic biomarkers are associated with each disease resulting from ancestral exposure to pesticides (Fig. 1). There are two thousand DMRs associated with the multiple disease condition, where 
A Prostate Disease DMR Associated Gene Correlations

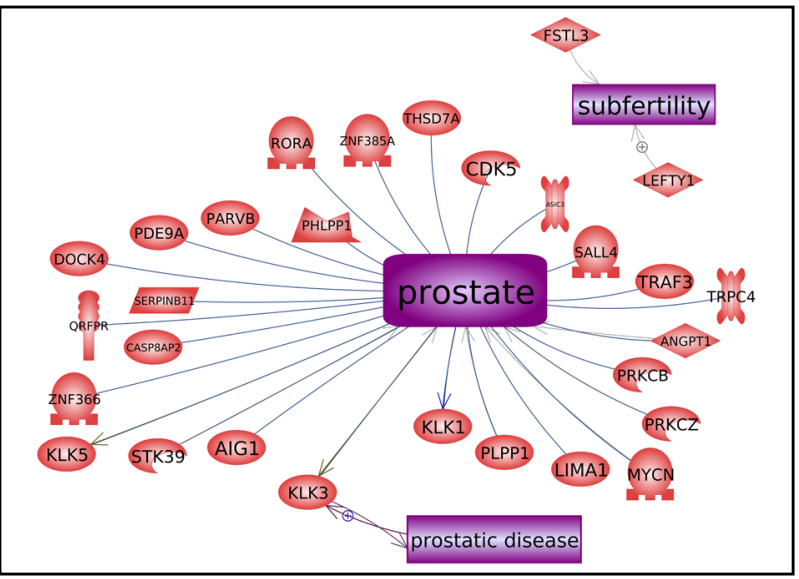

B Kidney Disease DMR Associated Gene Correlations

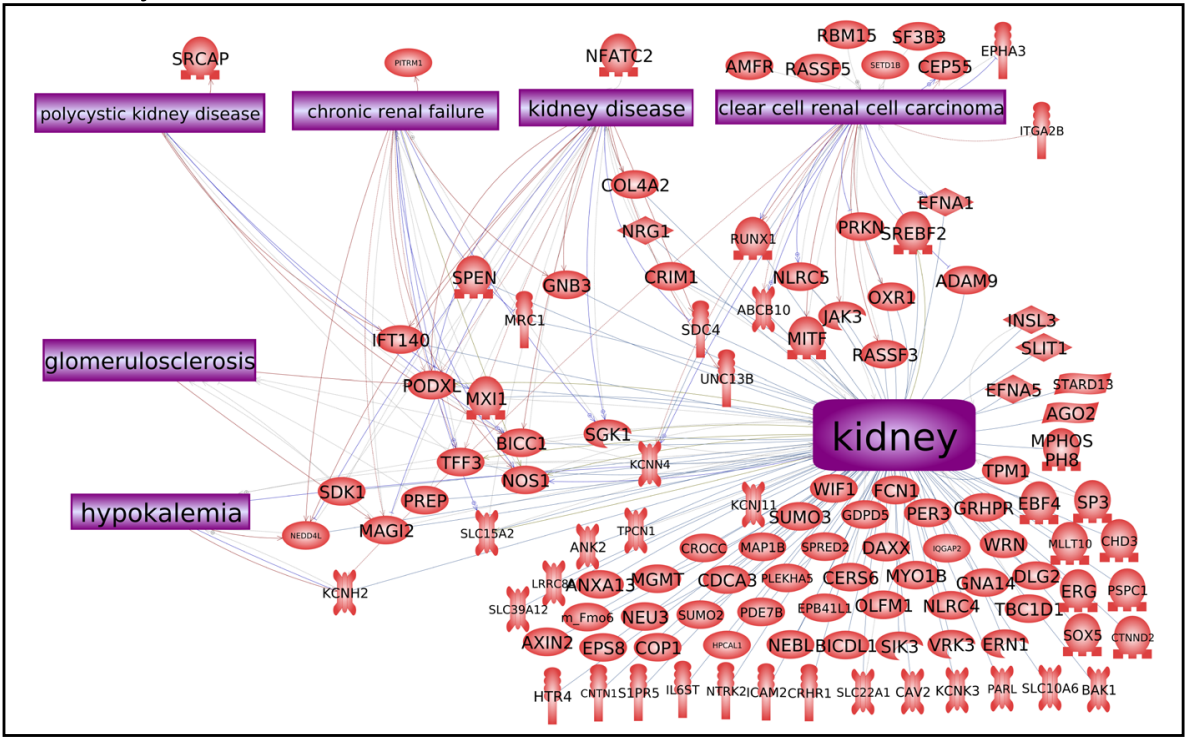

C Testis Disease DMR Associated Gene Correlations

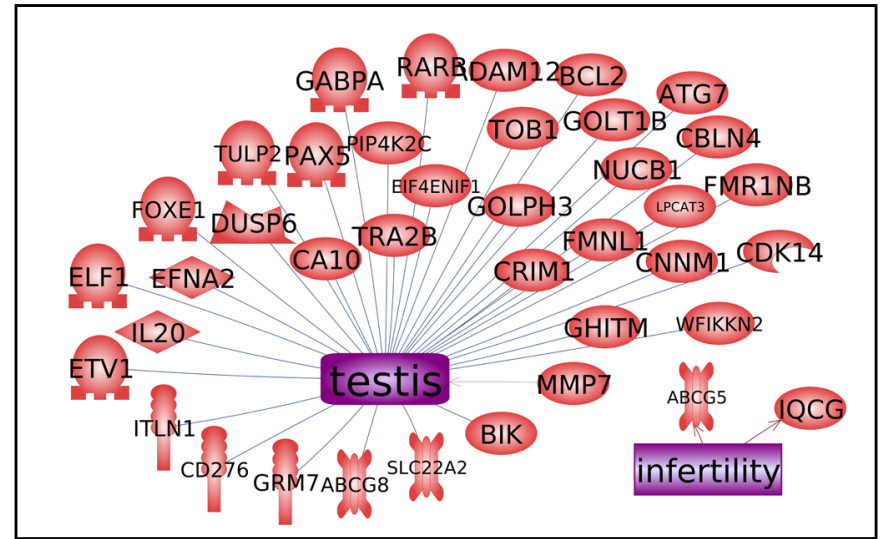

Fig. 7 Specific disease DMR associated gene correlation with previously identified disease genes. a Epimutation associated prostate disease genes. b Epimutation associated kidney disease genes. c Epimutation associated testis disease genes. The gene functional category shapes are identified as follows inset in Fig. 8 


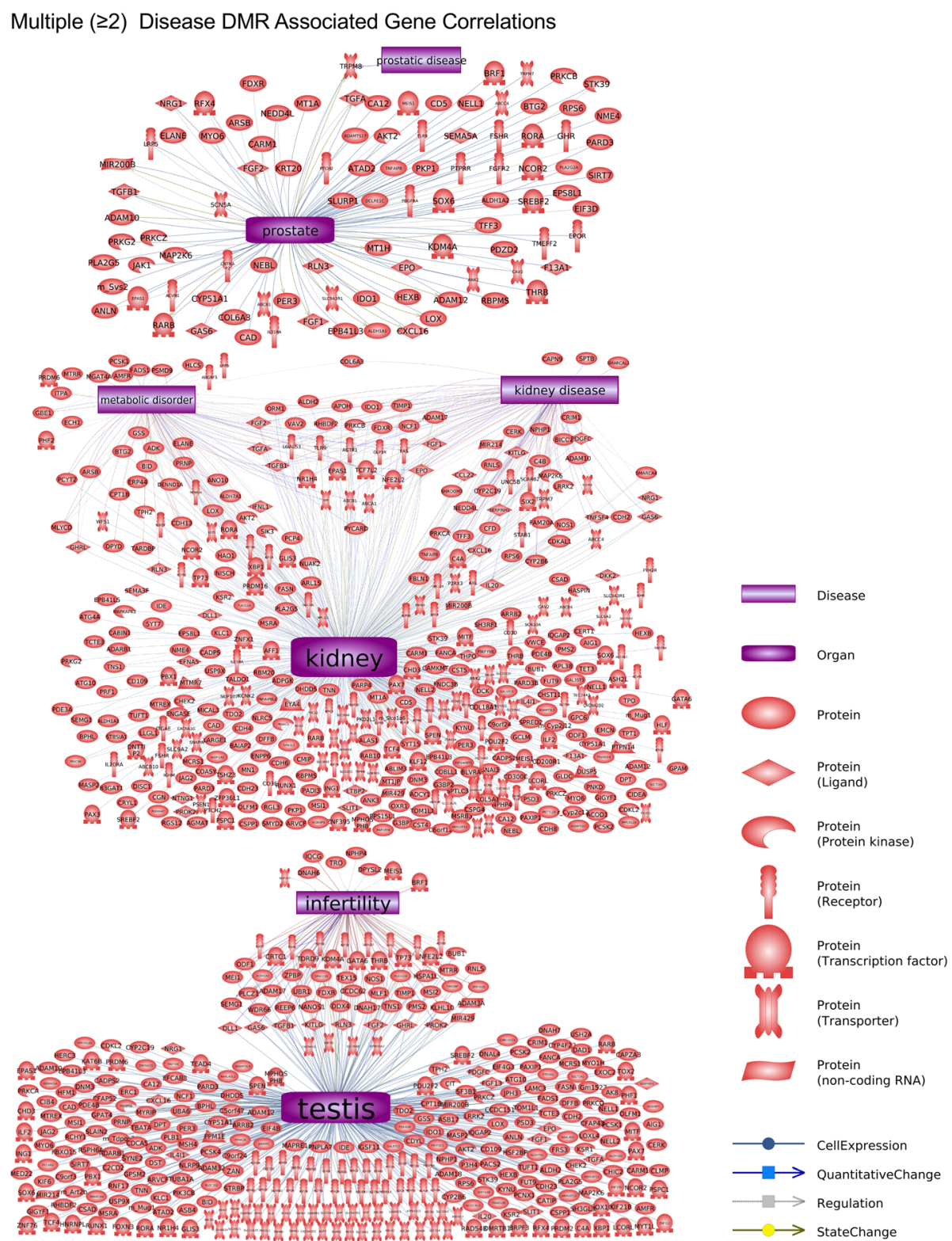

Fig. 8 Multiple disease DMR associated gene correlations with previously identified disease genes. The disease categories and gene identified shapes are presented. Gene functional category shapes presented in the inset

individual animals each exhibit multiple diseases. These epimutations are distributed widely across the genome (Fig. 2) leading to the conclusion that the epigenetic effect of the ancestral exposure are epigenome-wide. The transgenerational disease specific DMRs identified were found to be predominantly unique for the individual disease with no DMRs in common, Fig. 5. An extended overlap of DMRs for two disease comparisons shows between 7 and 34\% overlap with a relaxed significance level. Overlaps between individual and multiple diseases are higher, ranging between 22 and $50 \%$. The overlapping DMRs at $p<0.05$ also had no common DMRs between disease specific DMRs at $p<1 \mathrm{e}-04$. Therefore, no common DMR among the different transgenerational disease DMR biomarkers was identified. Observations suggest a common set of epimutations is not present between different diseases to alter general disease susceptibility. Although suggestions of such general molecular impacts for disease susceptibility may exist, the current study suggests predominately disease specific epimutations. This supports the potential ability of epigenetic biomarkers to be used in the future as disease diagnostics. These transgenerational disease DNA methylations alterations helps provide an explanation for the system- 
wide health effects of exposure to pesticides. This is exemplified by the Gulf War GWI population, which often has exposure to permethrin and DEET, among other chemicals $[11-13,76]$. Exposure to these toxicant chemicals results in a direct, multigenerational, and transgenerational epigenome-wide effects [33], and this is associated with increased incidence of negative health effects and disease.

A limitation of the current study was the low numbers of animals with a specific individual disease. Although an edgeR $p$-value was used to identify and analyze the disease associated DMRs, further analyses adjusting for multiple testing using the false discovery rate (FDR) resulted in FDR $p$-values for the disease epimutations of $>$ 0.1 in all comparisons except the multiple disease phenotype. The low sample number is likely the most important limitation in the current analysis. Potential higher variability in the data needs to be considered even though higher edgeR values were used, but this does not address multiple testing corrections. Future studies will need to use higher $\mathrm{n}$-values and/or better statistical models to reduce this FDR analysis limitation [63-68].

\section{Conclusions}

The current study used an epigenome-wide association analysis to identify an epigenetic signature of transgenerational disease present in sperm [33]. The biomarkers identified herein may potentially be used to asses paternal transmission of disease susceptibilities to future generations. Preconception diagnoses could be used to determine health trajectories for offspring of exposed individuals. This could be particularly important among populations known to experience higher and more chronic levels of exposure to pesticides, such as military and minority populations [12, 22, 32]. DNA methylation alterations are found in the sperm of agricultural workers [27], another population known to experience higher levels of pesticides exposure. These epigenetic biomarkers associated with disease among ancestrally exposed populations will potentially provide a crucial tool for assessing the health effects in later life for the current generation and the health prospects for future generations.

\section{Supplementary information}

Supplementary information accompanies this paper at https://doi.org/10. 1186/s12940-020-00666-y.

Additional file 1K Supplemental Table S1. DMR Site List Prostate $p<1 \mathrm{e}-04$. DMR name, chromosome, start, stop, length, number signature windows, minimum $p$-value, max log-fold change, CpG number, CpG density, gene annotation, and gene category are presented. Supplemental Table S2. DMR Site List Kidney $p<1 \mathrm{e}-04$. DMR name, chromosome, start, stop, length, number signature windows, minimum p-value, max log-fold change, CpG number, CpG density, gene annotation, and gene category are presented. Supplemental Table S3. DMR Site List Testis $p<1$ e-04. DMR name, chromosome, start, stop, length, number signature windows, minimum p-value, max log-fold change, CpG number, CpG density, gene annotation, and gene category are presented. Supplemental Table S4. DMR Site List Multiple $p<1$ e-04. DMR name, chromosome, start, stop, length, number signature windows, minimum $p$-value, max log-fold change, CpG number, CpG density, gene annotation, and gene category are presented.

\section{Abbreviations}

DEET: N,N-diethyl-meta-toluamide; EWAS: Epigenome-wide association study; DMRs: DNA methylation regions; GWI: Gulf War Illness; NOAEL: No observable adverse effect level; LOAEL: Lowest observable adverse effect level; DMSO: Dimethyl sulfoxide; BMI: Body mass index; MeDIP: Methylated DNA immunoprecipitation; MT: Mitochondrial DNA; PCA: Principal component analyses; FDR: False discovery rate; $H$ \& E: Hematoxylin, and eosin; WADDL: Washington Animal Disease Diagnostic Laboratory; QC: Quality control; PBS: Phosphate buffer saline; NGS: Next generation sequencing

\section{Acknowledgments}

We acknowledge Ms. Michelle Pappalardo, Mr. Ryan Thompson, Ms. Skylar Shea Davidson, Ms. Makena Horne, Ms. Emma Impala, and Ms. Rachel LaRosa for technical assistance. We acknowledge Ms. Amanda Quilty for editing and Ms. Heather Johnson for assistance in preparation of the manuscript. We thank the Genomics Core laboratory at WSU Spokane for sequencing data. This study was supported by John Templeton Foundation (50183 and 61174) (https://templeton.org/) grants to MKS and NIH (ES012974) (https://www.nih. gov/) grant to MKS. The funders had no role in study design, data collection and analysis, decision to publish, or preparation of the manuscript.

\section{Authors' contributions}

JLMT: Molecular analysis, data analysis, wrote and edited manuscript. DB: Bioinformatic analysis, data analysis, edited manuscript. MBM: Molecular analysis, edited manuscript. EN: Animal studies, cell isolations, data analysis, edited manuscript. MKS: Conceived, oversight, obtained funding, data analysis, wrote and edited manuscript. The authors read and approved the final manuscript.

\section{Funding}

This study was supported by John Templeton Foundation (50183 and 61174) (https://templeton.org/) grants to MKS and NIH (ES012974) (https://www.nih. gov/) grant to MKS. The funders had no role in study design, data collection and analysis, decision to publish, or preparation of the manuscript.

\section{Availability of data and materials}

All molecular data has been deposited into the public database at NCBI (GEO \# GSE158254) and R code computational tools available at GitHub (https://github.com/skinnerlab/MeDIP-seq) and www.skinner.wsu.edu.

\section{Ethics approval and consent to participate}

All experimental protocols for the procedures with rats were pre-approved by the Washington State University Animal Care and Use Committee (IACUC approval \# 2568). All methods were performed in accordance with the relevant guidelines and regulations.

Consent for publication

Not applicable.

\section{Competing interests}

The authors declare they have no competing interests.

Received: 1 July 2020 Accepted: 14 October 2020

Published online: 04 November 2020

\section{References}

1. Alavanja MC. Introduction: pesticides use and exposure extensive worldwide. Rev Environ Health. 2009;24(4):303-9.

2. Topping CJ, Aldrich A, Berny P. Overhaul environmental risk assessment for pesticides. Science. 2020;367(6476):360-3. 
3. EPA. https://www3.epa.gov/pesticides/chem_search/reg_actions/ reregistration/fs_PC-109701_1-Jun-06.pdf: U.S. Environmental Protection Agency; 2017 [Available from: https://www.epa.gov/insect-repellents/deet.

4. Casida JE, Gammon DW, Glickman AH, Lawrence $\sqcup$. Mechanisms of selective action of pyrethroid insecticides. Annu Rev Pharmacol Toxicol. 1983;23:413-38.

5. Costa LG, Giordano G, Guizzetti M, Vitalone A. Neurotoxicity of pesticides: a brief review. Front Biosci. 2008;13:1240-9.

6. Jellali R, Zeller P, Gilard F, Legendre A, Fleury MJ, Jacques S, et al. Effects of DDT and permethrin on rat hepatocytes cultivated in microfluidic biochips: metabolomics and gene expression study. Environ Toxicol Pharmacol. 2018; 59:1-12.

7. Wang X, Martinez MA, Dai M, Chen D, Ares I, Romero A, et al. Permethrininduced oxidative stress and toxicity and metabolism. A review. Environ Res. 2016:149:86-104

8. Cardona B, Rudel RA. US EPA's regulatory pesticide evaluations need clearer guidelines for considering mammary gland tumors and other mammary gland effects. Mol Cell Endocrinol. 2020;110927. https://doi.org/10.1016/j. mce.2020.110927.

9. Silva Pinto BG, Marques Soares TK, Azevedo Linhares M, Castilhos GN. Occupational exposure to pesticides: genetic danger to farmworkers and manufacturing workers - a meta-analytical review. Sci Total Environ. 2020; 748:141382.

10. Saito H, Hara K, Tanemura K. Prenatal and postnatal exposure to low levels of permethrin exerts reproductive effects in male mice. Reprod Toxicol. 2017;74:108-15.

11. Abu-Qare AW, Abou-Donia MB. Combined exposure to DEET (N,N-diethylm-toluamide) and permethrin: pharmacokinetics and toxicological effects. J Toxicol Environ Health B Crit Rev. 2003;6(1):41-53.

12. Mostafalou S, Abdollahi M. Pesticides and human chronic diseases: evidences, mechanisms, and perspectives. Toxicol Appl Pharmacol. 2013; 268(2):157-77.

13. Hoy JB, Cornell JA, Karlix JL, Tebbett IR, van Haaren F. Repeated coadministrations of pyridostigmine bromide, DEET, and permethrin alter locomotor behavior of rats. Vet Hum Toxicol. 2000;42(2):72-6.

14. Navarrrete V, Rodriguez A, Galera L, Garate EA, Villarreal F, Ramirez-Sanchez I. Exposure of rats to Permethrin, Pyridostigmine or diethyl-M-Toluamide (DEET) attenuates skeletal muscle function. FASEB J. 2020;34(S1):1.

15. Phillips KF, Deshpande LS. Repeated low-dose organophosphate DFP exposure leads to the development of depression and cognitive impairment in a rat model of gulf war illness. Neurotoxicology. 2016;52:127-33.

16. Hattiangady B, Mishra V, Kodali M, Shuai B, Rao X, Shetty AK. Object location and object recognition memory impairments, motivation deficits and depression in a model of gulf war illness. Front Behav Neurosci. 2014;8:78.

17. Ojo JO, Abdullah L, Evans J, Reed JM, Montague H, Mullan MJ, et al. Exposure to an organophosphate pesticide, individually or in combination with other gulf war agents, impairs synaptic integrity and neuronal differentiation, and is accompanied by subtle microvascular injury in a mouse model of gulf war agent exposure. Neuropathology. 2014;34(2):109-27.

18. Parihar VK, Hattiangady B, Shuai B, Shetty AK. Mood and memory deficits in a model of gulf war illness are linked with reduced neurogenesis, partial neuron loss, and mild inflammation in the hippocampus. Neuropsychopharmacology. 2013;38(12):2348-62

19. Zakirova Z, Tweed M, Crynen G, Reed J, Abdullah L, Nissanka N, et al. Gulf war agent exposure causes impairment of long-term memory formation and neuropathological changes in a mouse model of gulf war illness. PLoS One. 2015;10(3):e0119579.

20. Nilsson E, Sadler-Riggleman I, Skinner MK. Environmentally induced epigenetic Transgenerational inheritance of disease. Environ Epigenet. 2018; 4(2):1-13 dvy016.

21. Shen H, Main KM, Virtanen HE, Damggard IN, Haavisto AM, Kaleva M, et al. From mother to child: investigation of prenatal and postnatal exposure to persistent bioaccumulating toxicants using breast milk and placenta biomonitoring. Chemosphere. 2007:67(9):S256-62.

22. Whyatt RM, Rauh V, Barr DB, Camann DE, Andrews HF, Garfinkel R, et al. Prenatal insecticide exposures and birth weight and length among an urban minority cohort. Environ Health Perspect. 2004;112(10):1125-32.

23. Van Maele-Fabry G, Lantin AC, Hoet P, Lison D. Childhood leukaemia and parental occupational exposure to pesticides: a systematic review and meta-analysis. Cancer Causes Control. 2010;21(6):787-809.
24. McCarrey JR, Lehle JD, Raju SS, Wang Y, Nilsson EE, Skinner MK. Tertiary Epimutations - a novel aspect of epigenetic Transgenerational inheritance promoting genome instability. PLoS One. 2016;11(12):1-15 e0168038.

25. Skinner MK. Environmental stress and epigenetic transgenerational inheritance. BMC Med. 2014;12(1):153.

26. Lind L, Penell J, Luttropp K, Nordfors L, Syvanen AC, Axelsson T, et al. Global DNA hypermethylation is associated with high serum levels of persistent organic pollutants in an elderly population. Environ Int. 2013;59:456-61.

27. Howard TD, Hsu FC, Chen H, Quandt SA, Talton JW, Summers P, et al. Changes in DNA methylation over the growing season differ between North Carolina farmworkers and non-farmworkers. Int Arch Occup Environ Health. 2016;89(7):1103-10.

28. Huen K, Yousefi P, Bradman A, Yan L, Harley KG, Kogut K, et al. Effects of age, sex, and persistent organic pollutants on DNA methylation in children. Environ Mol Mutagen. 2014:55(3):209-22.

29. Anway MD, Cupp AS, Uzumcu M, Skinner MK. Epigenetic transgenerational actions of endocrine disruptors and male fertility. Science. 2005;308(5727): $1466-9$

30. Jacobs W, Ann O, Amuta AO, Jeon KC. Health information seeking in the digital age: an analysis of health information seeking behavior among US adults. Cogent Soc Sci. 2017:3(1):1302785 1-11.

31. Ben Maamar M, Sadler-Riggleman I, Beck D, McBirney M, Nilsson E, Klukovich $\mathrm{R}$, et al. Alterations in sperm DNA methylation, non-coding RNA expression, and histone retention mediate vinclozolin-induced epigenetic transgenerational inheritance of disease. Environ Epigenet. 2018;4(2):1-19 dvy010.

32. Rothstein MA, Harrell HL, Marchant GE. Transgenerational epigenetics and environmental justice. Environ Epigenet. 2017;3(3):dvx011.

33. Manikkam M, Tracey R, Guerrero-Bosagna C, Skinner M. Pesticide and insect repellent mixture (Permethrin and DEET) induces epigenetic

Transgenerational inheritance of disease and sperm Epimutations. Reprod Toxicol. 2012;34(4):708-19.

34. Nilsson E, King SE, McBirney M, Kubsad D, Pappalardo M, Beck D, et al. Vinclozolin induced epigenetic transgenerational inheritance of pathologies and sperm epimutation biomarkers for specific diseases. PLoS One. 2018; 13(8):1-29 e0202662

35. Skinner MK, Ben Maamar M, Sadler-Riggleman I, Beck D, Nilsson E, McBirney $\mathrm{M}$, et al. Alterations in sperm DNA methylation, non-coding RNA and histone retention associate with DDT-induced epigenetic transgenerational inheritance of disease. Epigenetics Chromatin. 2018;11(1):8 1-24.

36. Kubsad D, Nilsson EE, King SE, Sadler-Riggleman I, Beck D, Skinner MK. Assessment of glyphosate induced epigenetic Transgenerational inheritance of pathologies and sperm Epimutations: generational toxicology. Sci Rep. 2019;9(1):6372.

37. McBirney M, King SE, Pappalardo M, Houser E, Unkefer M, Nilsson E, et al. Atrazine induced epigenetic Transgenerational inheritance of disease, lean phenotype and sperm Epimutation pathology biomarkers. PLoS One. 2017; 12(9):1-37 e0184306

38. Manikkam M, Guerrero-Bosagna C, Tracey R, Haque MM, Skinner MK. Transgenerational actions of environmental compounds on reproductive disease and identification of epigenetic biomarkers of ancestral exposures. PLoS One. 2012;7(2):1-12 e31901.

39. Skinner MK, Nilsson E, Sadler-Riggleman I, Beck D, McCarrey JR. Transgenerational sperm DNA methylation Epimutation developmental origins following ancestral Vinclozolin exposure. Epigenetics. 2019;14(7):721-39.

40. King SE, McBirney M, Beck D, Sadler-Riggleman I, Nilsson E, Skinner MK. Sperm Epimutation biomarkers of obesity and pathologies following DDT induced epigenetic Transgenerational inheritance of disease. Environ Epigenet. 2019;5(2):1-15 dvz008.

41. Ben Maamar M, Beck D, Nilsson E, Kubsad D, Skinner MK. Glyphosate induced Transgenerational DNA methylation and histone retention sperm epigenetic biomarkers for disease. Epigenetcs. 2020; In press.

42. Nilsson EE, Anway MD, Stanfield J, Skinner MK. Transgenerational epigenetic effects of the endocrine disruptor vinclozolin on pregnancies and female adult onset disease. Reproduction. 2008;135(5):713-21.

43. Skinner MK, Manikkam M, Guerrero-Bosagna C. Epigenetic transgenerational actions of environmental factors in disease etiology. Trends Endocrinol Metab. 2010;21(4):214-22.

44. Tracey R, Manikkam M, Guerrero-Bosagna C, Skinner M. Hydrocarbons (jet fuel JP-8) induce epigenetic transgenerational inheritance of obesity, reproductive disease and sperm epimutations. Reprod Toxicol. 2013;36:104-16. 
45. Anway MD, Leathers C, Skinner MK. Endocrine disruptor vinclozolin induced epigenetic transgenerational adult-onset disease. Endocrinology. 2006; 147(12):5515-23

46. Guerrero-Bosagna C, Settles M, Lucker B, Skinner M. Epigenetic transgenerational actions of vinclozolin on promoter regions of the sperm epigenome. PLoS One. 2010;5(9):1-17 e13100.

47. Skinner MK, Manikkam M, Tracey R, Guerrero-Bosagna C, Haque MM, Nilsson E. Ancestral dichlorodiphenyltrichloroethane (DDT) exposure promotes epigenetic transgenerational inheritance of obesity. BMC Med. 2013;11(228): $1-16$.

48. Manikkam M, Tracey R, Guerrero-Bosagna C, Skinner M. Plastics derived endocrine disruptors (BPA, DEHP and DBP) induce epigenetic Transgenerational inheritance of obesity, reproductive disease and sperm Epimutations. PLoS One. 2013;8(1):1-18 e55387.

49. Manikkam M, Tracey R, Guerrero-Bosagna C, Skinner MK. Dioxin (TCDD) induces epigenetic transgenerational inheritance of adult onset disease and sperm epimutations. PLoS One. 2012;7(9):1-15 e46249.

50. Manikkam M, Haque MM, Guerrero-Bosagna C, Nilsson E, Skinner MK. Pesticide methoxychlor promotes the epigenetic transgenerational inheritance of adult onset disease through the female germline. PLoS One. 2014;9(7):1-19 e102091.

51. Anway MD, Skinner MK. Transgenerational effects of the endocrine disruptor vinclozolin on the prostate transcriptome and adult onset disease. Prostate. 2008;68(5):517-29.

52. Taylor JA, Richter CA, Ruhlen RL, Vom Saal FS. Estrogenic environmental chemicals and drugs: mechanisms for effects on the developing male urogenital system. J Steroid Biochem Mol Biol. 2011;127(1-2):83-95.

53. McAllister EJ, Dhurandhar NV, Keith SW, Aronne LJ, Barger J, Baskin M, et al. Ten putative contributors to the obesity epidemic. Crit Rev Food Sci Nutr. 2009;49(10):868-913.

54. Xie F, Zhang R, Yang C, Xu Y, Wang N, Sun L, et al. Long-term neuropeptide $Y$ administration in the periphery induces abnormal baroreflex sensitivity and obesity in rats. Cell Physiol Biochem. 2012;29(1-2):111-20.

55. Phillips LK, Prins JB. The link between abdominal obesity and the metabolic syndrome. Curr Hypertens Rep. 2008;10(2):156-64.

56. Huang $\Pi \mathrm{J} \mathrm{J}$, Yanagimachi R. Inner acrosomal membrane of mammalian spermatozoa: its properties and possible functions in fertilization. Am J Anat. 1985;174(3):249-68.

57. Calvin HI. Isolation of subfractionation of mammalian sperm heads and tails. Methods Cell Biol. 1976;13:85-104.

58. Bolger AM, Lohse M, Usadel B. Trimmomatic: a flexible trimmer for Illumina sequence data. Bioinformatics. 2014;30(15):2114-20.

59. Langmead B, Salzberg SL. Fast gapped-read alignment with bowtie 2. Nat Methods. 2012;9(4):357-9.

60. Li H, Handsaker B, Wysoker A, Fennell T, Ruan J, Homer N, et al. The sequence alignment/map format and SAMtools. Bioinformatics. 2009;25(16): 2078-9.

61. Lienhard M, Grimm C, Morkel M, Herwig R, Chavez L. MEDIPS: genome-wide differential coverage analysis of sequencing data derived from DNA enrichment experiments. Bioinformatics. 2014;30(2):284-6.

62. Robinson MD, McCarthy DJ, Smyth GK. edgeR: a bioconductor package for differential expression analysis of digital gene expression data. Bioinformatics. 2010:26(1):139-40.

63. Nilsson R, Bjorkegren J, Tegner J. On reliable discovery of molecular signatures. BMC Bioinformatics. 2009:10:38.

64. Jung SH. Sample size and power calculation for molecular biology studies. Methods Mol Biol. 2010;620:203-18.

65. Bretz F, Landgrebe J, Brunner E. Multiplicity issues in microarray experiments. Methods Inf Med. 2005:44(3):431-7.

66. Yang $\mathrm{H}$, Churchill $\mathrm{G}$. Estimating p-values in small microarray experiments. Bioinformatics. 2007;23(1):38-43.

67. Higdon R, van Belle G, Kolker E. A note on the false discovery rate and inconsistent comparisons between experiments. Bioinformatics. 2008;24(10): 1225-8.

68. Devlin B, Roeder K, Wasserman L. Analysis of multilocus models of association. Genet Epidemiol. 2003;25(1):36-47.

69. Durinck S, Spellman PT, Birney E, Huber W. Mapping identifiers for the integration of genomic datasets with the R/bioconductor package biomaRt. Nat Protoc. 2009;4(8):1184-91.

70. Cunningham F, Amode MR, Barrell D, Beal K, Billis K, Brent S, et al. Ensemb 2015. Nucleic Acids Res. 2015;43(Database issue):D662-9.
71. da Huang W, Sherman BT, Lempicki RA. Systematic and integrative analysis of large gene lists using DAVID bioinformatics resources. Nat Protoc. 2009; 4(1):44-57.

72. Mi H, Muruganujan A, Casagrande JT, Thomas PD. Large-scale gene function analysis with the PANTHER classification system. Nat Protoc. 2013; 8(8):1551-66.

73. Toynton K, Luukinen B, Buhl K, Stone D. Permethirn technical fact sheetOregon State University Extension Services; 2009.

74. Kim KH, Kabir E, Jahan SA. Exposure to pesticides and the associated human health effects. Sci Total Environ. 2017;575:525-35.

75. Sapbamrer R, Hongsibsong S. Effects of prenatal and postnatal exposure to organophosphate pesticides on child neurodevelopment in different age groups: a systematic review. Environ Sci Pollut Res Int. 2019;26(18):18267-90.

76. Abou-Donia MB, Wilmarth KR, Jensen KF, Oehme FW, Kurt TL. Neurotoxicity resulting from coexposure to pyridostigmine bromide, deet, and permethrin: implications of gulf war chemical exposures. J Toxicol Environ Health. 1996:48(1):35-56.

\section{Publisher's Note}

Springer Nature remains neutral with regard to jurisdictional claims in published maps and institutional affiliations.

Ready to submit your research? Choose BMC and benefit from:

- fast, convenient online submission

- thorough peer review by experienced researchers in your field

- rapid publication on acceptance

- support for research data, including large and complex data types

- gold Open Access which fosters wider collaboration and increased citations

- maximum visibility for your research: over $100 \mathrm{M}$ website views per year

At BMC, research is always in progress.

Learn more biomedcentral.com/submissions 